\title{
Beneficial effect of dose escalation and surgical debulking in patients with acromegaly treated with somatostatin analogs in a Romanian tertiary care center
}

\author{
Monica Livia Gheorghiu, ${ }^{1,2 *}$ Simona Găloiu, ${ }^{1,2 *}$ Mădălina Vintilă, ${ }^{1}$ Mariana Purice, ${ }^{1}$ \\ Dan Hortopan, ${ }^{1}$ Anda Dumitraşcu, ${ }^{1}$ Mihail Coculescut ${ }^{1,2}$ Cătălina Poiană ${ }^{1,2}$ \\ 1"C.I. Parhon" National Institute of Endocrinology, "2Carol Davila" University of Medicine and Pharmacy, Bucharest, \\ Romania \\ ${ }^{*}$ Authors with equal contribution
}

\begin{abstract}
BACKGROUND: Somatostatin analogs (SSA) are now considered standard therapy for acromegaly, as primary or adjunctive treatment after pituitary surgery. OBJECTIVE: To evaluate the efficacy of SSA and the effect of dose escalation in non-operated patients with acromegaly as compared to patients treated after pituitary surgery in a Romanian tertiary care center. DESIGN: Retrospective study of 73 consecutively evaluated patients with acromegaly treated with SSA, divided into 2 groups: 11 patients (4M/7F, 21-62 years) with primary treatment and 62 patients $(22 \mathrm{M} / 40 \mathrm{~F}, 21-68$ years) treated after surgery. They received Octreotide LAR 20-30 mg i.m./28 days or Lanreotide SR $30 \mathrm{mg}$ i.m./14/10/7 days. Random serum growth hormone (GH) was measured using IRMA, sensitivity $0.2-0.01 \mu \mathrm{g} / \mathrm{L}$ IGF-1 was measured using different assays and compared with ULN for age and sex. RESULTS: Overall, random GH $\leq 2.5 \mu \mathrm{g} / \mathrm{L}$ was attained in 39 patients $(53.4 \%)$ and optimal $\mathbf{G H} \leq 1 \mathrm{ng} / \mathrm{mL})$ in 30 patients $(41 \%)$, while normal IGF-1 was recorded in $22 / 72$ patients $(30.5 \%)$. The final random $\mathrm{GH} \leq 2.5 \mu \mathrm{g} / \mathrm{L}$ was achieved in $27.2 \%$ of non-operated patients (3/11) as compared with $58 \%(36 / 62)$ of patients treated medically after pituitary surgery, $p<0.05$. Escalation of doses of SSA applied in 43 patients improved the number of controlled patients by $5(12.1 \%, p=0.059)$ and the number of optimally controlled patients by $9.7 \%$. Of the 8 patients who switched from Lanreotide to Octreotide, 2 patients achieved GH normalization. CONCLUSION: The rate of biochemical control via SSA treatment in patients with acromegaly could be improved by rise of the SSA dose or by debulking surgery. Occasionally, substituting one SSA for another may be of benefit.
\end{abstract}

Key words: Acromegaly, Dose escalation, Pituitary surgery, Somatostatin analogs 


\section{INTRODUCTION}

Acromegaly is a rare disease usually caused by a $\mathrm{GH}$-secreting pituitary adenoma producing excess growth hormone $(\mathrm{GH})$ and insulin-like growth factor 1 (IGF-1). Uncontrolled acromegaly is associated with a two- to threefold increase in mortality compared with age- and sex-matched healthy controls. ${ }^{1-3}$ Death is due predominantly to cardio-cerebrovascular disease, respiratory disease and, in some studies, to malignancy. ${ }^{3}$ Controlling GH and IGF-1 hypersecretion is the primary goal of treatment in order to lower mortality rates. Earlier studies have indicated that random $\mathrm{GH}<2.5 \mu \mathrm{g} / \mathrm{L}$ (measured by radioimmunoassays) and normal serum IGF-1 are both correlated with a standardized mortality ratio close to that of the general population, ${ }^{2}$ the effect of GH normalization being more extensively reported in the literature. ${ }^{3}$

Recent consensus guidelines recommend more stringent values for 'cure' or control of acromegaly, i.e. random $\mathrm{GH}$ levels below $1 \mu \mathrm{g} / \mathrm{L}$ or OGTT nadir $\mathrm{GH}<1 \mu \mathrm{g} / \mathrm{L}$ or even $<0.4 \mu \mathrm{g} / \mathrm{L}$ (if measured by ultrasensitive immunoassays) and normal age-related IGF-1 levels., ${ }^{4,5}$ Treatment of acromegaly frequently requires a multimodality approach to control disease progression. Besides pituitary surgery, with better results being achieved in dedicated neurosurgical centers, ${ }^{6}$ somatostatin receptor ligands (somatostatin analogs, SSA) are now considered standard therapy for acromegaly, either as primary or adjunctive treatment. They suppress GH secretion by the pituitary and GH-secreting adenomas, decrease binding to hepatocyte $\mathrm{GH}$ receptors, inhibit hepatic IGF-1 synthesis and control tumor growth. ${ }^{7}$ Clinical studies with the most extensively used depot SSA, Octreotide LAR (OCT) and Lanreotide slow-release (LAN) have shown variable results. ${ }^{8}$ Conventional doses of Octreotide LAR (20-30 mg/month) induced biochemical control (GH levels $<2.5 \mu \mathrm{g} / \mathrm{L}$ ) between $42 \%$ and $72 \%$ and IGF-1 normalization in $38-67 \%$ of patients, respectively, ${ }^{9-11}$ while Lanreotide slow release (SR) reduced plasma GH levels in $49-54 \%$ of patients and normalized IGF-1 levels in 51-59\% of patients. ${ }^{12,13}$ Clinically significant tumor shrinkage has been reported in $66 \%$ of patients treated with OCT-LAN ${ }^{14}$ and in $32 \%$ of patients treated with LAN-SR or Autogel. ${ }^{15}$ Escalation of the SSA doses has been shown to improve biochemical control in patients resistant to conventional doses ${ }^{9,10,13}$ while demonstrating a similar tolerability profile. ${ }^{16}$

We analyzed retrospectively, in an unselected population of Romanian patients with acromegaly assessed in a single center, the efficacy of SSA treatment and the effect of progressive increase of SSA doses in patients not surgically treated as compared to patients treated with SSA after pituitary surgery.

\section{PATIENTS AND METHODS}

We evaluated 73 patients with acromegaly treated with SSA, admitted to the Department of Neuroendocrinology between 2007 and 2012. Patients with acromegaly and hyperprolactinemia treated with stable doses of dopamine-agonist were not excluded. The diagnosis of acromegaly was defined in all patients by high serum $\mathrm{GH}$ levels not suppressible $<1 \mu \mathrm{g} / \mathrm{L}$ after $75 \mathrm{~g}-2 \mathrm{~h}$ glucose load (OGTT) and high plasma IGF-1 levels for age.

\section{Patients were divided into 2 groups}

Group A included 11 patients with pre-surgery treatment with SSA: 4 men, 7 women, median age at diagnosis 42.0 years (range 21-62 years); one of these patients had had previous pituitary radiotherapy (high-voltage radiotherapy) 19 years before the SSA treatment and linear accelerator gamma-knife radiotherapy 7 months before the SSA treatment. Based on pituitary imaging, 10 patients had a macroadenoma, 1 patient had a microadenoma and in 5 patients the tumors had signs of invasion into the surrounding structures.

Group B included 62 patients who received treatment with SSA after pituitary surgery. Forty-one of these patients had also had previous radiotherapy. There were 22 men and 40 women, median age at diagnosis 40.50 years (range $21-68$ years). Before surgery, 57 patients had a macroadenoma (in 21 patients with signs of invasion into the surrounding structures), 4 patients had a microadenoma, while in 1 patient the initial tumor volume is unknown. At initiation of the SSA treatment, 35 patients had pituitary remnants $\geq 1$ $\mathrm{cm}, 27$ patients $<1 \mathrm{~cm}$.

All patients signed an informed consent form to approve diagnostic testing, treatment decision, 
methods for follow-up and treatment of the data for scientific purposes.

\section{Treatment}

In Romania, treatment with SSA is supported by the National Health Insurance House for patients with active acromegaly after pituitary surgery \pm radiotherapy or as primary therapy only for patients with macroadenomas $>2 \mathrm{~cm}$ in diameter or with clear signs of tumor invasion into the surrounding tissues. The patients were not selected for therapy based on their response to an acute test to Octreotide $0.1 \mathrm{mg}$ s.c.

The somatostatin analogs used were Octreotide - long-acting release (OCT- LAR) at doses of 20 $30 \mathrm{mg}$ i.m. at 28-day intervals or Lanreotide - slow release (LAN - SR) at doses of $30 \mathrm{mg}$ i.m. at 14, 10 or 7-day intervals. In all but 2 patients, the treatment was started with the lowest dose and was increased in patients who did not normalize GH and/or IGF-1, this determined after assessment of the response at 3-6 months. In 43 patients the response to treatment was assessed both on the low (OCT $20 \mathrm{mg}$ i.m./28 days or LAN $30 \mathrm{mg}$ i.m./14 days) and the higher dose (OCT $30 \mathrm{mg}$ i.m./28 days or LAN $30 \mathrm{mg}$ i.m./10 or 7 days). Thirty-seven patients had been initially treated with LAN-SR, 36 patients with OCT-LAR. Nine patients received both drugs consecutively and the responses to each treatment were compared.

\section{Criteria for disease control}

The patients were considered controlled if fasting $\mathrm{GH}$ levels were $\leq 2.5 \mu \mathrm{g} / \mathrm{L}$ in the presence of normal IGF-1 levels for sex and age. The subgroup of patients having at least one $\mathrm{GH}$ level $\leq 1 \mu \mathrm{g} / \mathrm{L}$ (either fasting or after $75 \mathrm{~g}$-OGTT) in the presence of normal IGF1 levels for sex and age was considered optimally controlled, as recommended by the latest diagnosis guidelines for acromegaly. ${ }^{4}$ During the study period, GH levels were determined in our center by different immunoradiometric assays. The assays sensitivity ranged accordingly (from 0.2 to $0.01 \mu \mathrm{g} / \mathrm{L}$ ). Random $\mathrm{GH}$ levels were measured either as a mean of a GH daily curve ( 4 samplings at 4 hours interval) or in the baseline blood sample from $75 \mathrm{~g}$-OGTT.

Serum IGF-1 was measured by different commercial assays in different laboratories. IGF-1 data are shown as measured serum values and as the ratio with the upper limit of the normal range for sex and age in each assay (ULN; normal $\leq 1$ ).

\section{SSA treatment side-effects}

Data were retrieved from the medical files of the patients.

\section{Tumor evaluation}

Tumor size was measured in the majority of patients via computed tomography $(\mathrm{CT})$ or via magnetic resonance imaging (MRI) studies. The images were reviewed by two experienced radiologists (D.H and A.D.). We calculated the tumor area using the ellipsoid formula (coronal vertical $\times$ transversal diameter $\times \pi / 4$ ). A reduction of at least $25 \%$ of the tumor area after treatment was considered significant.

\section{Statistical analyses}

The data were analyzed using SPSS software (version 11.0; SPSS Inc., Chicago, IL) and are reported as mean \pm standard deviation for variables with normal distribution or as median [range] in the case of deviations from normality. The ANOVA model and 2-tailed Student's t-test were used to compare the variables with a normally distributed value; the Mann-Whitney test was used for the parameters with skewed distribution. Spearman's coefficients with a 95\% confidence interval were calculated for correlations. Multivariate regression analysis then identified independent predictive parameters. The comparison between baseline and the final data was performed by the Wilcoxon matched pair test. The $\chi^{2}$ test was used for categorical variables. $P<0.05$ was considered statistically significant.

\section{RESULTS}

The characteristics of the patients and their tumors before treatment with somatostatin analogs are summarized in Table 1.

\section{SSA efficacy on GH and IGF-1 secretion}

The patients were evaluated before and during treatment with SSA for a period of $16 \pm 10.5$ months (range 3-44 months). At the final evaluation, 45 patients $(62 \%)$ were on high-dose SSA. SSA treatment induced a significant decrease of random serum $\mathrm{GH}$ (median) from $7.8 \mu \mathrm{g} / \mathrm{L}$ [1.2-176] to $2.3 \mu \mathrm{g} / \mathrm{L}$ [0.1-71.1], $\mathrm{p}$ $<0.001$, and of serum IGF-1 (median) from $2.48 \times$ 
Table 1. Baseline characteristics of patients with acromegaly treated with somatostatin analogs (SSA)

\begin{tabular}{|c|c|c|c|}
\hline & $\begin{array}{l}\text { SSA before surgery } \\
\qquad \mathbf{N}=\mathbf{1 1}\end{array}$ & $\begin{array}{c}\text { SSA after surgery } \\
\qquad N=62\end{array}$ & $\mathbf{p}$ \\
\hline Age at diagnosis (median, range) (years) & $42.00[21-62]$ & $40.50[21-68]$ & NS \\
\hline Sex & $4 \mathrm{M}: 7 \mathrm{~F}$ & $22 \mathrm{M}: 40 \mathrm{~F}$ & NS \\
\hline Previous radiotherapy, $\mathrm{n}(\%)$ & $1(9.09)$ & $41(66.12)$ & 0.001 \\
\hline SSA treatment duration (median, range) (months) & $9.00[3-17]$ & $15.00[3-44]$ & 0.007 \\
\hline Tumor size at diagnosis (n) & 10 macro, 1 micro $(<1 \mathrm{~cm})$ & 57 macro, 4 micro, 1 unknown & NS \\
\hline Tumor size before SSA (n) & 9 macro, 2 micro & 42 macro, 20 micro & NS \\
\hline Tumor area at diagnosis (median, range) $\left(\mathrm{cm}^{2}\right)$ & $3.41[0.51-9.97](\mathrm{n}=9)$ & $1.89[0.5-13.06](\mathrm{n}=58)$ & NS \\
\hline Tumor area before SSA(median, range) $\left(\mathrm{cm}^{2}\right)$ & $3.43[0.51-9.97]$ & $0.64[0.5-9.80]$ & $<0.05$ \\
\hline Invasive tumor, $\mathrm{n}(\%)$ & $5(45.4)$ & $21(33.8)$ & NS \\
\hline Random serum GH before SSA (median, range) $(\mu \mathrm{g} / \mathrm{L})$ & $25.10[4.35-176]$ & $6.80[1.2-162]$ & 0.09 \\
\hline Serum IGF-1 before SSA, $\times$ ULN (median, range) & $3.56[2.30-7.40]$ & $2.20[0.5-9.40]$ & $<0.05$ \\
\hline Treatment & $\begin{array}{c}\text { LAN-SR: } 1 \\
\text { OCT-LAR: } 10\end{array}$ & $\begin{array}{c}\text { LAN-SR: } 36 \\
\text { OCT-LAR: } 26 \\
\text { Both consecutively: } 9\end{array}$ & \\
\hline
\end{tabular}

Legend: ULN = IGF-1 upper limit of normal range for age, macro -macroadenoma, micro -microadenoma

ULN [0.5-9.4] to $1.46 \times \operatorname{ULN}[0.49-4.8], \mathrm{p}<0.001$.

Overall, random $\mathrm{GH} \leq 2.5 \mu \mathrm{g} / \mathrm{L}$ was recorded at the last evaluation in 39 patients $(53 \%)$ and optimal GH (any random or OGTT GH $\leq 1 \mu \mathrm{g} / \mathrm{L}$ ) in 30 patients $(41 \%)$, while normal IGF-1 was recorded in 22 patients (31\%). Both $\mathrm{GH} \leq 2.5 \mu \mathrm{g} / \mathrm{L}$ and normal IGF-1 were recorded in 18 patients $(25 \%)$ and optimal GH and normal IGF-1 in 19 patients $(26 \%)$.

The pre-treatment tumor area and random serum $\mathrm{GH}$ levels before treatment were independently pre- dictive for post-treatment $\mathrm{GH}$ levels (coeff. $\mathrm{B}=2.58$, 95\% CI [1.22-3.93], $\mathrm{p}<0.001$, and coeff. $\mathrm{B}=0.23$, $95 \%$ CI [0.14-0.31], $\mathrm{p}<0.001$, respectively).

\section{SSA efficacy in patients treated before or after pituitary surgery}

The comparison between operated and non-operated patients treated with SSA therapy is shown in Table 1 (baseline characteristics before treatment), Table 2 (efficacy of the treatment) and Figure 1.

Table 2. Results of the treatment with somatostatin analogs before or after pituitary surgery in patients with acromegaly

\begin{tabular}{lccc}
\hline & SSA before surgery & SSA after surgery & N \\
\hline Random serum GH $\mu \mathrm{g} / \mathrm{L}$, median [range] & $12.10[0.46-71.1]$ & $2.0[0.1-64.0]$ & $<0.05$ \\
Serum IGF-1 $\times \mathrm{ULN}$, median [range] & $2.30[1.5-4.8]$ & $0.49[0.4-4.1]$ & $<0.001$ \\
Random serum GH $\leq 2.5 \mu \mathrm{g} / \mathrm{L}$, no. $(\%)$ & $3 / 11(27.2 \%)$ & $36 / 62(58.0 \%)$ & $<0.05$ \\
Any serum GH $\leq 1 \mu \mathrm{g} / \mathrm{L}$, no. $(\%)$ & $1 / 11(9 \%)$ & $29 / 62(46.7 \%)$ & $<0.05$ \\
Normal serum IGF-1, no. $(\%)$ & 0 & $22 / 61(36.0 \%)$ & $<0.05$ \\
Controlled patients, no. $(\%)$ & 0 & $18 / 61(29.5 \%)$ & 0.06 \\
Optimally controlled patients, no. $(\%)$ & 0 & $19 / 61(31.1 \%)$ & $<0.05$
\end{tabular}

Legend: Controlled patients $=$ random serum $\mathrm{GH} \leq 2.5 \mu \mathrm{g} / \mathrm{L}$ and normal IGF-1 for age; optimally controlled patients $=$ any serum $\mathrm{GH}$ $\leq 1 \mu \mathrm{g} / \mathrm{L}$ and normal IGF-1 for age; no.: number; SSA: somatostatin analogs. 


\section{Group $A$}

Eleven patients who underwent SSA treatment without previous pituitary surgery had a follow-up of $9.0 \pm 4.3$ months (range $3-17$ ) and $8(73 \%)$ were on high-dose SSA at the last evaluation. Random GH (median) decreased during SSA from $25.10 \mu \mathrm{g} / \mathrm{L}$ [4.35 - 176] to $12.10 \mu \mathrm{g} / \mathrm{L}$ [0.46-71.1], $\mathrm{p}=0.09$ (Figure 1). IGF-1 (median) decreased from $3.56 \times$ ULN [2.3 $7.4]$ to $2.30 \times \mathrm{ULN}[1.5-4.8], \mathrm{p}<0.05$.

In group A, post-treatment $\mathrm{GH}$ levels were independently influenced by post-treatment tumor area (coeff. $\mathrm{B}=6.6,95 \% \mathrm{CI}[2.34-11.03], \mathrm{p}=0.008$ ) and with age at diagnosis (coeff. $\mathrm{B}=-0.95,95 \% \mathrm{CI}[-1.82$ --0.09 ], $\mathrm{p}=0.03$ ), i.e. younger age and larger tumor area were correlated to higher post-treatment GH levels. Post-treatment IGF-1 levels were independently related to post-treatment tumor area (coeff. $\mathrm{B}=0.35$, $95 \%$ CI [0.12-0.59], $\mathrm{p}=0.008$ )

\section{Group B}

Sixty-two patients treated after pituitary surgery were followed for a period of $17.2 \pm 10.8$ months (3-44), longer than for non-operated patients $(\mathrm{p}<0.05)$. The percentage of patients on high-dose SSA at the last evaluation was $60 \%$, similar to that in non-operated patients. Thirty-six patients were assessed on treatment with LAN-SR and 26 patients on treatment with OCT-LAR.

Random GH levels (median) decreased from 6.8 $\mu \mathrm{g} / \mathrm{L}[1.2-162]$ to $2.0 \mu \mathrm{g} / \mathrm{L}[0.1-64], \mathrm{p}<0.01$; IGF-1 levels (median) decreased from $2.20 \times$ ULN [0.5-9.4] to $0.49 \times \mathrm{ULN}[0.4-4.1], \mathrm{p}<0.01$.

In group B, post-treatment $\mathrm{GH}$ levels correlated independently only with pre-treatment GH levels, coeff. $\mathrm{B}=0.21,95 \% \mathrm{CI}[0.11-0.30], \mathrm{p}<0.001$. Posttreatment IGF-1 levels correlated with pre-treatment IGF-1 levels (coeff. B $=0.28,95 \%$ CI [0.15 - 0.42], $\mathrm{p}<0.001)$ and were inversely correlated to age at diagnosis (coeff. $\mathrm{B}=-0.02,95 \% \mathrm{CI}[-0.04--0.006]$, $\mathrm{p}=0.008)$.

Although pre-SSA treatment random GH levels were not significantly different in operated versus non-operated patients, pre-treatment IGF1 levels were higher in the non-operated group (Table 1).

The efficacy of SSA treatment was better in patients who underwent pituitary surgery before SSA treatment, as compared to primary SSA treatment: the operated patients achieved lower GH and IGF-1 levels and there were more patients with 'safe' random GH $\leq 2.5 \mu \mathrm{g} / \mathrm{L}$, with any serum $\mathrm{GH} \leq 1 \mu \mathrm{g} / \mathrm{L}$, with IGF-1 normalization or optimal disease control (any serum $\mathrm{GH} \leq 1 \mu \mathrm{g} / \mathrm{L}$ and normal IGF-1) (Table 2).
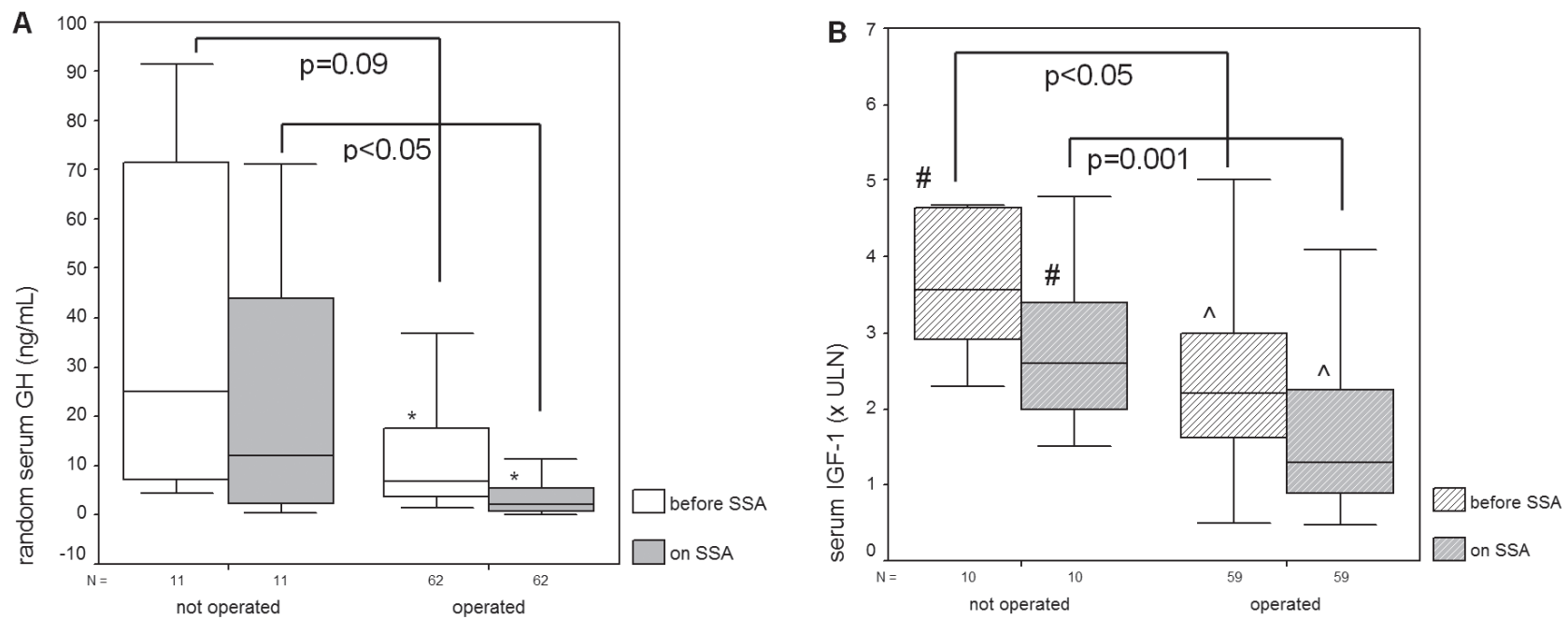

Figure 1. Random serum GH levels (left) and IGF-1 levels (right) before and during treatment with somatostatin analogs (SSA) in patients with acromegaly with or without a previous pituitary surgery. ${ }^{*} p<0.01, \# p<0.05, \wedge p<0.001$ for levels recorded before SSA versus those during SSA. 


\section{Effect of SSA dose increase on GH and IGF-1 secretion}

An increase in the SSA dosage was recorded in 43 patients: 8 patients from group A (OCT-LAR 30 $\mathrm{mg}$ in all patients) and 35 patients from group $\mathrm{B}$
(OCT-LAR $30 \mathrm{mg}$ in 17 patients, LAN-SR $30 \mathrm{mg}$ at 7 days in 14 patients and LAN-SR $30 \mathrm{mg}$ at 10 days in 4 patients). The results are presented in Table 3 and Figure 2.

High-dose SSA induced a significant supplemen-

Table 3. Treatment efficacy of low-dose versus high-dose somatostatin analogs in patients with acromegaly

\begin{tabular}{|c|c|c|c|c|}
\hline Parameter & $\begin{array}{l}\text { Before SSA vs } \\
\text { low-dose SSA }\end{array}$ & p1 & $\begin{array}{c}\text { Low-dose vs } \\
\text { high-dose SSA }\end{array}$ & p2 \\
\hline Random serum GH $(\mu \mathrm{g} / \mathrm{L})$ & $7.8[1.2-176]$ & & $4.70[0.29-98.70]$ & \\
\hline \multirow[t]{2}{*}{ Median [range] } & $3.60[0.10-98.70]$ & $<0.01$ & $3.35[0.24-64]$ & $<0.05$ \\
\hline & $\mathrm{n}=71$ & & $\mathrm{n}=43$ & \\
\hline Serum IGF-1 × ULN & $2.8 \pm 1.5$ & & $2.3 \pm 1.2$ & \\
\hline \multirow[t]{2}{*}{ Mean \pm SD } & $1.9 \pm 1.2$ & $<0.001$ & $1.9 \pm 1.04$ & $<0.05$ \\
\hline & $\mathrm{n}=65$ & & $\mathrm{n}=41$ & \\
\hline \multirow[t]{2}{*}{ Random serum $\mathrm{GH} \leq 2.5 \mu \mathrm{g} / \mathrm{L}$, no./no. evaluable patients (\%) } & $10 / 71(14.0 \%)$ & \multirow{2}{*}{$<0.001$} & $10 / 43(23.2 \%)$ & \multirow{2}{*}{0.06} \\
\hline & $29 / 71(40.8 \%)$ & & $19 / 43(44.1 \%)$ & \\
\hline \multirow[t]{2}{*}{ Any serum $\mathrm{GH} \leq 1 \mu \mathrm{g} / \mathrm{L}$, no./no. evaluable patients ( $\%)$} & $2 / 71(2.8 \%)$ & \multirow{2}{*}{$<0.001$} & $4 / 43(9.3 \%)$ & \multirow{2}{*}{ NS } \\
\hline & $25 / 71(35.2 \%)$ & & $10 / 43(23.2 \%)$ & \\
\hline \multirow[t]{2}{*}{ Normal serum IGF-1, no./no. evaluable patients ( $\%)$} & $1 / 65(1.5 \%)$ & \multirow{2}{*}{$<0.001$} & $4 / 41(9.7 \%)$ & \multirow{2}{*}{ NS } \\
\hline & 18 / $65(27.6 \%)$ & & $7 / 41(17.0 \%)$ & \\
\hline \multirow[t]{2}{*}{ Controlled patients, no./no. evaluable patients ( $\%)$} & $0 / 65(0.0 \%)$ & \multirow{2}{*}{$<0.001$} & $0 / 41(0.0 \%)$ & \multirow{2}{*}{0.059} \\
\hline & 12 / $65(18.4 \%)$ & & $5 / 41(12.1 \%)$ & \\
\hline \multirow[t]{2}{*}{ Optimally controlled patients, no./no. evaluable patients (\%) } & $0 / 65(0.0 \%)$ & \multirow{2}{*}{$<0.001$} & $0 / 41(0.0 \%)$ & \multirow{2}{*}{ NS } \\
\hline & $13 / 65(20.0 \%)$ & & $4 / 41(9.7 \%)$ & \\
\hline
\end{tabular}

Controlled patients $=$ random serum $\mathrm{GH} \leq 2.5 \mu \mathrm{g} / \mathrm{L}$ and normal IGF-1 for age; optimally controlled patients $=$ any serum $\mathrm{GH} \leq 1 \mu \mathrm{g} / \mathrm{L}$ and normal IGF-1 for age; $\mathrm{p} 1$ = comparison between values before SSA and those after low-dose SSA; 2 = comparison between values on low-dose SSA and those on high-dose SSA; no.: number; SSA: somatostatin analogs.
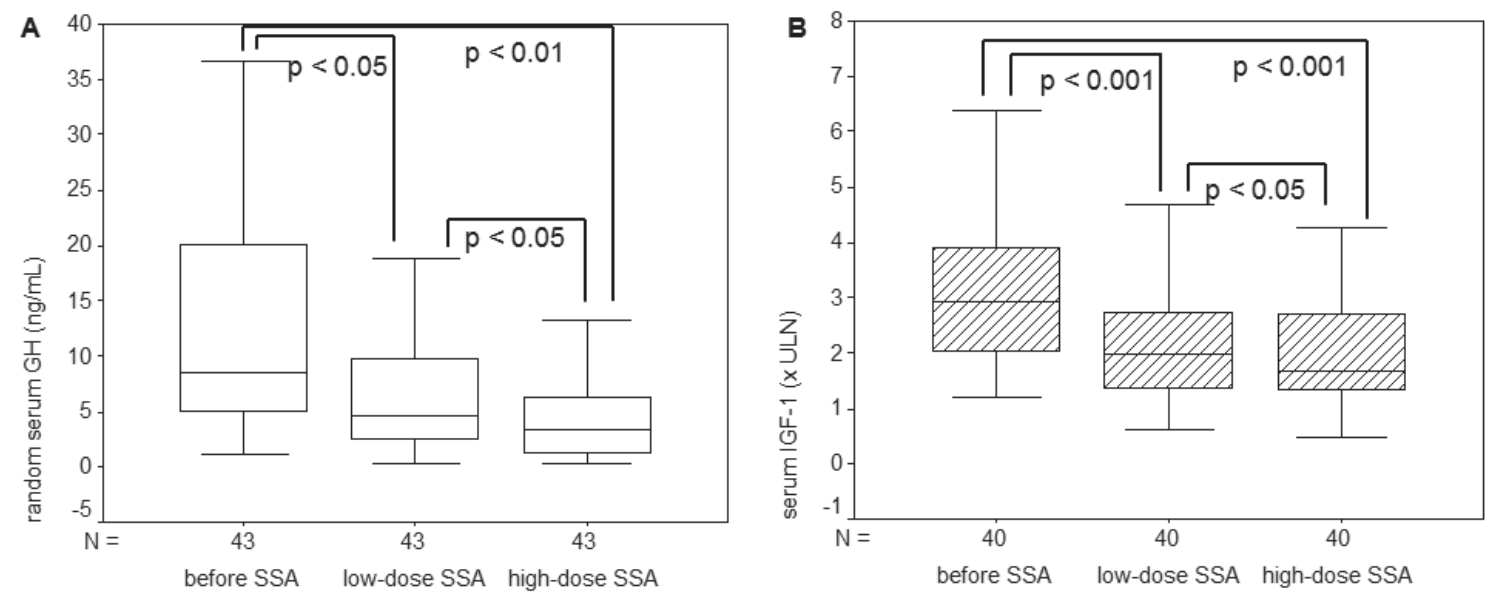

Figure 2. Random serum GH levels (A) and IGF-1 levels (B) before and during treatment with low-dose and high-dose somatostatin analogs (SSA) in patients with acromegaly. 
tary decrease of random GH levels and of IGF-1 $(\mathrm{xULN})$, an excess of random GH normalization in $19 \%$ of patients, of optimal GH normalization in $14 \%$ of patients and of IGF- 1 normalization in $9 \%$ of patients. High-dose SSA improved the number of controlled patients by $12 \%(\mathrm{p}=0.059)$ and the number of optimally controlled patients by $9.7 \%$.

In patients evaluated during both low-dose and high-dose SSA ( $n=43$ for $\mathrm{GH}$ and 40 for IGF-1), the percentage decrease of random serum GH after highdose SSA ( $52 \pm 37 \%)$ was significantly higher than after low-dose SSA $(39 \pm 32 \%, \mathrm{p}<0.05)$, while IGF- 1 had a non-significant change $(35 \pm 26 \%$ compared to $31 \pm 28 \%$ ).

High-dose SSA tended to decrease random GH levels $(\mathrm{p}=0.059)$ and IGF-1 $(\times \mathrm{ULN})(\mathrm{p}=0.066)$ more than low-dose SSA, especially in patients who underwent pituitary surgery (Figure 3 ), where it also improved the number of controlled patients by 5 $(15 \%)(\mathrm{p}=0.053)$.

\section{Comparison of LAN-SR with OCT-LAR in previously operated patients}

An indirect comparison of the two somatostatin analogs in previously operated patients was possible, since 36 patients were evaluated on LAN-SR (36 patients on low dose, 23 patients on high dose) and 26 patients were evaluated on OCT-LAR (24 patients on low dose, 14 on high dose).

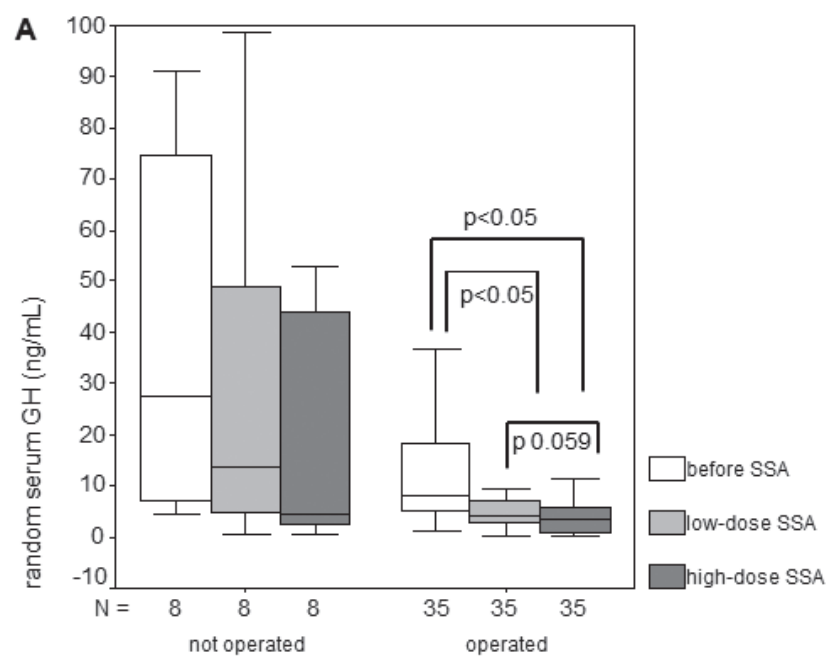

The 2 groups did not differ significantly regarding age at diagnosis, tumor characteristics (initial and pretreatment tumor area, invasiveness, $\%$ of macroadenomas), pre-treatment random serum GH and IGF-1 levels, although previous radiotherapy was recorded in more patients with LAN-SR (30 patients, $83 \%$ ) than in those with OCT-LAR (11 patients, 42\%), p <0.01.

Treatment efficacy was similar in both groups, i.e. GH levels, IGF-1 levels and the percentage of GH or IGF-1 decrease, whether on low-dose or on high-dose SSA (data not shown).

The frequency of side effects was similar in patients treated with LAN versus OCT. The most common complaints, mild in intensity, were: diarrhea in 3 patients $(4.1 \%)$, constipation in 2 patients $(2.7 \%)$, floating, abdominal pain in 2 patients $(2.7 \%)$, nausea in 1 patient (1.3\%), and arthralgia in 1 patient $(1.7 \%)$. Cholelithiasis, including biliary sludge, was detected by ultrasound in $21 / 73$ patients ( $28 \%$ ), hyperglycemia in patients without previous diabetes and glucose intolerance was detected in 11 patients (15\%), modest hematologic disorders in 13 patients $(17.8 \%), 1$ transient eczema in 1 patient (1.7\%).

\section{Comparison of LAN-SR with OCT-LAR in the same patient}

In 9 patients with previous pituitary surgery one drug was replaced by the other one due to insufficient control of the disease (in all 9) and to a skin

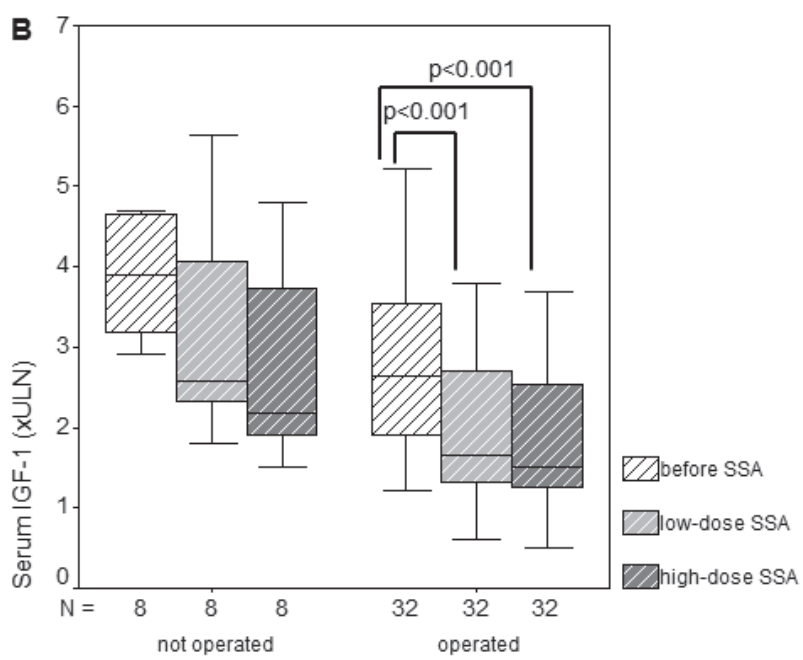

Figure 3. Random serum GH levels (A) and IGF-1 levels (B) before and during treatment with low-dose and high-dose somatostatin analogs (SSA) in patients with acromegaly with or without previous pituitary surgery. 
reaction. There were 5 women and 4 men, all with macroadenomas at diagnosis; age at diagnosis was 36 years (22-42 years). We compared similar doses for both drugs, (low doses in 3 patients, high doses in 6 patients) after similar periods of treatment with each drug (3-6 months). All but 1 patient switched from LAN-SR to OCT-LAR. In the patient who switched from OCT to LAN, random GH decreased from 2.59 $\mu \mathrm{g} / \mathrm{L}$ after the first drug to $2.1 \mu \mathrm{g} / \mathrm{L}$ on the second drug, while IGF-1 decreased from $3.76 \times$ ULN to $2.4 \times$ ULN.

In 8 patients who switched from LAN to OCT, there was a non-significant reduction of random $\mathrm{GH}$ and IGF-1, but GH normalization occurred in 2 more patients $(25 \%)$ and disease control was attained in 2 patients $(25 \%)$ (Table 4$)$.

\section{DISCUSSION}

\section{SSA efficacy on GH and IGF-1 secretion}

Treatment goals in acromegaly include normalization of serum GH and IGF-1 levels, tumor disappearance with normal pituitary function and, finally, improved survival. Surgery is usually the first-line treatment, but frequently adjunctive medical treat- ment with SSA is used. "Real life" studies with SSA (as our study) reported lower rates of GH and IGF-1 normalization than the controlled ones. ${ }^{5}$ In a large UK cohort, 'safe' GH levels actually achieved across all courses of medical therapy were around $75 \%$ of cases even in long-term medical treatment courses ( $>3$ years), while GH and IGF-1 both normalized in no more than $55 \%$ on SSA. ${ }^{17}$ A meta-analysis reviewing more than 600 patients showed GH levels $<2.5$ $\mu \mathrm{g} / \mathrm{L}$ and normal IGF- 1 in $57 \%$ and $67 \%$ of patients, respectively, on Octreotide LAR, and in $48 \%$ and $47 \%$, respectively, on Lanreotide depot. ${ }^{18}$ In the data from the Belgian Register of Acromegaly, ${ }^{19}$ adjunctive medical therapy post-surgery and/or radiotherapy normalized IGF-1 in 53\%, GH in 59\% and both parameters in $42 \%$ of 121 patients. Similarly, in our population of 73 unselected Romanian patients with acromegaly, followed for 16 months, control of GH was attained in $53.4 \%$ and normal IGF-1 was recorded in $30.5 \%$ of patients. However, according to the latest recommended criteria for disease control, both parameters were normalized only in a quarter of the patients.

The reasons for this apparent "resistance" to SSA could be the lack of compliance of the patient to the therapy, inconsistent monitoring, insufficient dose,

Table 4. Effect of changing LAN-SR with OCT-LAR due to lack of disease control in patients with acromegaly

\begin{tabular}{|c|c|c|c|c|c|c|c|c|c|}
\hline \multirow[b]{2}{*}{ Patient } & \multicolumn{5}{|c|}{ Random serum GH $(\mu \mathrm{g} / \mathrm{L})$} & \multicolumn{4}{|c|}{ Serum IGF-1 (× ULN) } \\
\hline & $\begin{array}{l}\text { Before } \\
\text { SSA } 1\end{array}$ & $\begin{array}{c}\text { On } \\
\text { SSA } 1\end{array}$ & $\begin{array}{l}\text { Washout } \\
\text { (months) }\end{array}$ & $\begin{array}{l}\text { Before } \\
\text { SSA } 2\end{array}$ & $\begin{array}{c}\text { On } \\
\text { SSA } 2\end{array}$ & $\begin{array}{l}\text { Before } \\
\text { SSA } 1\end{array}$ & $\begin{array}{c}\text { On } \\
\text { SSA } 1\end{array}$ & $\begin{array}{l}\text { Before } \\
\text { SSA } 2\end{array}$ & $\begin{array}{c}\text { On } \\
\text { SSA2 }\end{array}$ \\
\hline 1 & 146 & 24.5 & 3 & 146 & 18.7 & 4 & 3 & 4 & 3.67 \\
\hline 2 & 19.5 & 3.6 & 3 & 5.9 & 1.3 & 2 & 1.1 & 2.22 & 0.98 \\
\hline 3 & 5.2 & 7.2 & 3 & 11.4 & 1.2 & 3.3 & 3.18 & 3.39 & 1.46 \\
\hline 4 & 3.5 & 7.4 & 0 & 3.5 & 3.3 & 2.23 & 2.07 & 2.23 & 1.63 \\
\hline 5 & 6.3 & 1.6 & 0 & 6.3 & 0.5 & 1.5 & 1.5 & 1.5 & 0.57 \\
\hline 6 & 7.6 & 2.5 & 9 & 4.9 & 0.77 & 1.91 & 1.87 & 2.23 & 1.97 \\
\hline 7 & 160 & 36.9 & $8(\operatorname{Re}-o p)$ & 70.6 & 64 & 2.9 & 2.52 & 2.93 & 3.07 \\
\hline 8 & 11.2 & 21.13 & 4 & 14.6 & 21.1 & 2.97 & 2.79 & 2.8 & 1.92 \\
\hline Mean \pm SD & $44.9 \pm 67$ & $13.1 \pm 13$ & & $33 \pm 51$ & $13.8 \pm 22$ & $2.6 \pm 0.8$ & $2.2 \pm 0.7$ & $2.6 \pm 0.8$ & $1.9 \pm 1$ \\
\hline Normal GH $\leq 2.5 \mu \mathrm{g} / \mathrm{L} /$ Normal IGF-1 & - & 2 & & - & 4 & - & - & - & 2 \\
\hline Controlled disease & - & - & & - & 2 & & & & \\
\hline Optimally controlled & - & - & & - & 1 & & & & \\
\hline
\end{tabular}

In patient no.7, GH before the first treatment was measured in a different laboratory than the other assessments; the patient was reoperated transphenoidally during the wash-out period (Re-op). 
availability of certain therapies (e.g., in Romania the use of SSA as primary therapy is authorized only for large macroadenomas), inter- and intra-variability of common assays for GH and/or IGF-1, tumor phenotype or real drug resistance. ${ }^{20}$ The most important factor influencing the treatment outcome is pretreatment $\mathrm{GH}$ level, as has been shown in this study and in others. ${ }^{17}$

\section{SSA efficacy in patients treated before or after pituitary surgery}

Although some studies reported that preoperative SSA treatment could result in better surgical cure rate in patients with acromegaly, other studies did not support these findings (cited in ${ }^{19,21}$ ). A recent meta-analysis of 35 studies enrolling 2629 patients showed that surgery was associated with a higher remission rate than primary SSA treatment $(67 \%$ vs $45 \%$; $\mathrm{P}<0.02$ ), especially in long-term follow-up. ${ }^{22}$ SSA pretreatment seems to be beneficial mainly in centers recording a low neurosurgical cure rate. ${ }^{23}$

In our center, patients treated with SSA after pituitary surgery achieved significantly lower GH and IGF-1 levels, while there was a higher percentage of patients with $\mathrm{GH} \leq 2.5 \mu \mathrm{g} / \mathrm{L}$ and with optimal disease control (29\%), compared to the primary SSA treatment group, in which none of the patients was optimally controlled. The percentage of patients treated with high-dose SSA was similar between the two groups.

Possible explanations for the better results in operated patients could be a significantly longer duration of SSA treatment (average 17 vs 9 months), a smaller tumor mass at treatment initiation $\left(1.2 v s 3.8 \mathrm{~cm}^{2}\right)$ or more frequent radiotherapy (in $66 \% v s 9 \%$ of patients) in this group. The small number of patients treated pre-operatively ${ }^{11}$ is also a limit of this comparison. However, it appears that pituitary surgery and radiotherapy, albeit apparently unsuccessful, may enhance the control achieved on SSA treatment, as has also been suggested by other authors. ${ }^{17}$

\section{Effect of SSA dose increase on GH and IGFI secretion}

Recent guidelines suggest that in patients with inadequate control after 6 months of SSA treatment, dose escalation of SRL therapy should be performed at 3-month intervals based on patient response. ${ }^{5}$ There was no increase in the incidence of the adverse events with SSA dose escalation, compared with conventional doses, even on high doses of SSA (e.g., OCT LAR up to $60 \mathrm{mg} / 28 \mathrm{~h}$ ). ${ }^{4,15}$ A 2-year dose-escalation study using Octreotide LAR as first-line therapy in 56 patients with acromegaly demonstrated a clear benefit of dose increase from $20 \mathrm{mg} / \mathrm{month}$ to up to $40 \mathrm{mg} / \mathrm{month}: 86 \%$ of patients attained GH levels of $<2.5 \mu \mathrm{g} / \mathrm{L}, 84 \%$ achieved normal IGF-1 levels and $21 / 32(65 \%)$ of inadequately controlled patients finally achieved remission. ${ }^{24}$ Similarly, in our patients high-dose SSA used in 43/73 patients improved the number of controlled patients by $5(12.1 \%, \mathrm{p}=0.059)$.

\section{Comparison of LAN-SR with OCT-LAR}

In this study we observed that OCT-LAR and LAN-SR are equivalent in reducing GH and IGF-1 levels in operated patients. In 8 patients who switched from LAN-SR to OCT-LAR due to incomplete or lack of disease control, 2 of the patients $(25 \%)$ attained disease control and 2 additional patients (25\%) achieved GH normalization after a similar period of follow-up for both drugs and concordant dose level. However, this was not a controlled or head-to-head study and confounding factors cannot be systematically excluded. Data from switching or crossover studies in the literature show that Octreotide LAR efficacy seems to be generally similar to that of Lanreotide ATG and modestly better than that of Lanreotide SR..$^{25-27}$

\section{CONCLUSION}

Our study confirmed that somatostatin analogs are effective in the biochemical control of Romanian patients with acromegaly in about $50 \%$ of the cases. The treatment response rate could be improved by escalation of the SSA dose or by debulking surgery. Occasionally, substituting one somatostatin analog to another has shown some benefit.

\section{ACKNOWLEDGMENTS}

The authors are grateful to Andra Caragheorgheopol for IGF-1 measurements. Neurosurgeons Ligia Tataranu and Vasile Ciubotaru are acknowledged for doing the neurosurgery. 
The authors dedicate this paper to Professor Mihail Coculescu, builder of clinical Neuroendocrinology in Romania, inspiring teacher and mentor, who passed away before this paper was published.

\section{CONFLICT OF INTEREST}

The authors do not have any conflict of interest.

\section{FUNDING}

This work received financial support through the project entitled "CERO - Career profile: Romanian Researcher", grant number POSDRU/159/1.5/S/135760, co-financed by the European Social Fund for Sectoral Operational Programme Human Resources Development 2007-2013.

\section{REFERENCES}

1. Ayuk J, Clayton RN, Holder G, Sheppard MC, Stewart PM, Bates AS, 2004 Growth hormone and pituitary radiotherapy, but not serum insulin-like growth factor-I concentrations, predict excess mortality in patients with acromegaly. J Clin Endocrinol Metab 89: 1613-1617.

2. Holdaway IM, Bolland MJ, Gamble GD, 2008 A metaanalysis of the effect of lowering serum levels of GH and IGF-I on mortality in acromegaly. Eur J Endocrinol 159: 89-95.

3. Sherlock M, Ayuk J, Tomlinson JW, et al, 2010 Mortality in patients with pituitary disease. Endocr Rev 31: 301-342.

4. Giustina A, Chanson P, Bronstein MD, et al, 2010 A consensus on criteria for cure of acromegaly. J Clin Endocrinol Metab 95: 3141-3148.

5. Giustina A, Chanson P, Kleinberg D, et al, 2014 Expert consensus document: A consensus on the medical treatment of acromegaly. Nat Rev Endocrinol 10: 243-248.

6. Sala E, Ferrante E, Locatelli M, et al, 2014 Diagnostic features and outcome of surgical therapy of acromegalic patients: experience of the last three decades. Hormones (Athens) 13: 95-103.

7. Murray RD, Kim K, Ren S-G, Chelly M, Umehara Y, Melmed S, 2004 Central and peripheral actions of somatostatin on the growth hormone-IGF-I axis. J Clin Invest 114: 349-356.

8. Fleseriu M, 2011 Clinical efficacy and safety results for dose escalation of somatostatin receptor ligands in patients with acromegaly: A literature review. Pituitary 14: 184-193.

9. Colao A, Ferone D, Marzullo P, et al, 2001 Long-term effects of depot long-acting somatostatin analog octreotide on hormone levels and tumor mass in acromegaly.
J Clin Endocrinol Metab 86: 2779-2786.

10. Cozzi R, Montini M, Attanasio R, et al, 2006 Primary treatment of acromegaly with octreotide LAR: a longterm (up to nine years) prospective study of its efficacy in the control of disease activity and tumor shrinkage. J Clin Endocrinol Metab 91: 1397-1403.

11. Mercado M, Borges F, Bouterfa H, et al 2007 A prospective, multicentre study to investigate the efficacy, safety and tolerability of octreotide LAR (long-acting repeatable octreotide) in the primary therapy of patients with acromegaly. Clin Endocrinol (Oxf) 66: 859-868.

12. Toledano Y, Rot L, Greenman Y, et al, 2009 Efficacy of long-term lanreotide treatment in patients with acromegaly. Pituitary 12: 285-293.

13. Melmed S, Cook D, Schopohl J, Goth MI, Lam KSL, Marek J, 2010 Rapid and sustained reduction of serum growth hormone and insulin-like growth factor-1 in patients with acromegaly receiving lanreotide Autogel therapy: a randomized, placebo-controlled, multicenter study with a 52 week open extension. Pituitary 13: 18-28.

14. Giustina A, Mazziotti G, Torri V, Spinello M, Floriani I, Melmed S, 2012 Meta-analysis on the effects of octreotide on tumor mass in acromegaly. PLoS One 7.

15. Mazziotti G, Giustina A, 2010 Effects of lanreotide SR and Autogel on tumor mass in patients with acromegaly: A systematic review. Pituitary 13: 60-67.

16. Ludlam WH, Anthony L, 2011 Safety review: Dose optimization of somatostatin analogs in patients with acromegaly and neuroendocrine tumors. Adv Ther 28: 825-841.

17. Howlett TA, Willis D, Walker G, Wass JAH, Trainer PJ, 2013 Control of growth hormone and IGF1 in patients with acromegaly in the UK: responses to medical treatment with somatostatin analogues and dopamine agonists. Clin Endocrinol (Oxf) 79: 689-699.

18. Freda PU, Katznelson L, Van Der Lely AJ, Reyes CM, Zhao S, Rabinowitz D, 2005 Long-acting somatostatin analog therapy of acromegaly: A meta-analysis. J Clin Endocrinol Metab 90: 4465-4473.

19. Bex M, Abs R, T'Sjoen G, et al, 2007 AcroBel - The Belgian registry on acromegaly: A survey of the "reallife" outcome in 418 acromegalic subjects. Eur J Endocrinol 157: 399-409.

20. Melmed S, Kleinberg DL, Bonert V, Fleseriu M, 2014 Acromegaly: assessing the disorder and navigating therapeutic options for treatment. Endocr Pract 20 Suppl 1: 7-17.

21. Fougner SL, Bollerslev J, Svartberg J, Oksnes M, Cooper J, Carlsen SM, 2014 Preoperative octreotide treatment of acromegaly: long-term results of a randomised controlled trial. Eur J Endocrinol 171: 229-235.

22. Abu Dabrh AM, Mohammed K, Farah WH, et al, 2014 Surgical interventions and medical treatments in treatment-naïve patients with acromegaly: systematic review and meta-analysis. J Clin Endocrinol Metab 
99: 4003-4014.

23. Pita-Gutierrez F, Pertega-Diaz S, Pita-Fernandez S, et al, 2013 Place of preoperative treatment of acromegaly with somatostatin analog on surgical outcome: a systematic review and meta-analysis. PLoS One 8: e61523.

24. Colao A, Pivonello R, Auriemma RS, Galdiero M, Savastano S, Lombardi G, 2007 Beneficial effect of dose escalation of octreotide-LAR as first-line therapy in patients with acromegaly. Eur J Endocrinol 157: 579-587.

25. Tutuncu Y, Berker D, Isik S, et al, 2012 Comparison of octreotide LAR and lanreotide autogel as post-operative medical treatment in acromegaly. Pituitary 15: 398-404.

26. Auriemma RS, Pivonello R, Galdiero M, et al, 2008 Octreotide-LAR vs lanreotide-SR as first-line therapy for acromegaly: a retrospective, comparative, head-tohead study. J Endocrinol Invest 31: 956-965.

27. Chanson P, Boerlin V, Ajzenberg C, et al, 2000 Comparison of octreotide acetate LAR and lanreotide SR in patients with acromegaly. Clin Endocrinol (Oxf) 53: $577-586$. 